\title{
Contribution on Improving Power Resilience in the Healthcare Facility
}

\author{
Hartungi, Rusdy and Commins, L. J.
}

\begin{abstract}
Focused on predicting and preventing electrical failures, this paper presents methodologies to those responsible for managing the electrical supplies in Healthcare and other similar environments.

Particular attention has been directed to developing ways of exploiting the known relationships between thermal and electrical engineering disciplines as a means of monitoring and informing a timely intervention.

There are two major studies presented in this paper which contrubute resilience in specific areas of Healtcare Facility. The first study is focusing on thermography, it is enhanced with an application of the finite difference method for modelling thermal performance under adverse conditions has been analysed.Thsi methos could provide a more robust solution for appraising new and existing installations. Study shows that early identification.

A second study was carried out to examine the use of weather forecast-based electrical site load predictions as a possible precursor to automated load shed control which found reliable correlation between a site's peak electrical load and the peak outside air temperature. The use of weather forecast-based electrical site load will help reducing unnecessary tripping of the power supply and this increase resilience.
\end{abstract}

Index Terms-Preventative Maintenance, Electrical Resilience, Thermography, Energy Management, NHS Trust.

\section{INTRODUCTION}

P rotecting energy should be the key underlining feature for $P$ any business continuity initiative. The security of our energy supplies is often characterized by the concept of resilience. One of the primary concerns is 'redundancy'. A typical approach taken is to install an additional, redundant supply capacity of at least $100 \%$. The particular risks associated with the loss of engineering services directly supporting the healthcare environment, allow a strong case for a systematic resilience based approach in their design and management to be made. Based on experimental data collected within a large acute Trust, the principle focus of this paper is to develop innovative techniques to help predict and prevent electrical failure in certain applications.

Manuscript received August 23, 2017; revised September 22 and October 18; accepted November 26, 2017.

Hartungi, Rusdy is with London South Bank University ((e-mail: hartungr@lsbu.ac.uk).

Commins, Liam. J., is with Estates Manager, The Royal Free London NHS Foundation Trust (e-mail: liam.commins@nhs.net).
Resilience is an important subject in the Healthcare sector as, unlike most large energy consuming organization, where commercial factors have the greatest influence on investment decisions, the security and preservation of human life must also be weighed up. [2] Summarizes the levels of clinical risk into 5 groups; $1-5$ in order of criticality. Categories 4 and 5 are defined by the safety of a person's life in the event of a power outage being either 'compromised' or 'endangered' respectively. Also advised is that designers focus on installing the 'single point of failure' as close to the load as possible.

With respect to energy consumption, [2] reports that energy use in the healthcare sector as a whole is growing at a rate of 3$6 \%$ per year. Looking closer at large, acute Trusts, a statistical analysis of the Estates Return Information Collection [3], which holds information collected from all UK healthcare premises since 1999/00, shows clear correlation between the proportions of gross internal area (GIA) used for patient care, and annual energy consumption. The statistics also show that an average overall increase of $1.4 \%$ a year in these premises, has been observed over the past 10 years, see Fig. 1.

In a recent report authored by [4], the organizational objectives for the next 5 years are set out. The effect of the NHS England proposals on existing hospital infrastructures, is likely to mean an increased patient density and consequently as the data in Fig. 1 would suggest, a substantially greater electrical load. The incorporation of more specialist surgical units is likely to pose the single greatest engineering challenge; primarily due to the high ventilation air change rates required to maintain a low infection risk environment.

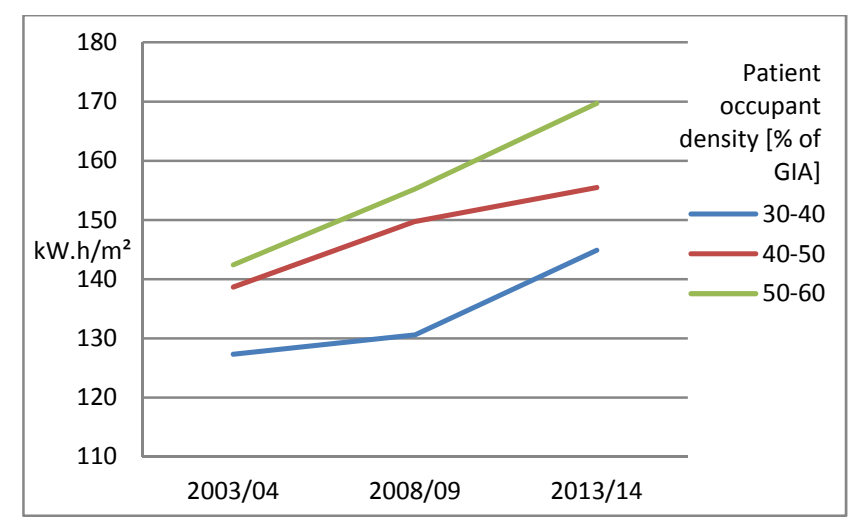

Fig. 1. Average annual energy consumption per square meter against patient occupant density, Source [3]. 


\section{AIM AND OBJECTIVES}

As previously mentioned, the studies to be presented are focused on predicting and preventing electrical failure. These investigations will be carried out with a view towards establishing better management systems, for monitoring the situation and determining when to act. The chosen areas of research are as follows.

- A study of an enhanced methodology for thermographic analysis, aimed at appraising the integrity of electrical connections when the system is modelled at its maximum load condition

- A site load study, to construct a more intelligible picture of a healthcare building's load profile and determine if, and to what extent, a reliable correlation exists between it and the thermal environment, thus making it more predictable

\section{Thermal OF ELECTRICAL CONDUCTORS}

Thermographic analysis has been a popular method of nondestructive testing for many years, and is a proven technique for identifying points of stress in an electrical distribution system. Hotspots captured on thermographic images can effectively highlight developing faults such as failing contacts, loose connections and insulation breakdown before they develop into serious failures. However in some circumstances the process entails significant and sometimes unacceptable risk both to the thermographer and the customer. Another limitation of thermography is that the radiated heat measured from a failing joint, is proportional to the square of the current; hence the operating current being carried by the conductors at the time of the observation, will have a substantial bearing on its visibility to the inspector.

Due to cost considerations, it is very likely that a customer will primarily specify thermographic analysis on those parts of the electrical system which present the greatest risk to business continuity. Rising busbar systems, transformers, UPS systems and common, dual-fed distribution panels are potential single points of failure, and tend to be prioritized for this reason. This study focusses exclusively on electrical connections on uninsulated bus bar systems; however the same techniques could also be applied to any other electrical connection where a detailed dimensional and material assessment can be made. A phase to phase or earth fault within a busbar system would be catastrophic; moreover, the severity of the damage sustained due to the dissipation of fault energy, is likely to increase the recovery time dramatically. Attention for this study will be focused on heat dissipation, in particular the temperature gradient that exists in the vicinity of a high resistance joint, where the probability of phase crossover becomes increasingly likely with distance. Fig. 2, a thermographic image taken at the test site, shows an example of this condition. This study seeks a means to model and analyse the transport of heat through typical bus bar connections at full-load conditions using the finite difference method and commonplace PC software. Using only material dimensions, and the maximum permissible current-carrying capacity, as outlined by [5], the aim is to define an upper limit on measured joint resistance so as to prevent catastrophic insulation failures caused by excessive localised heat. The technique shall allow a worst-case scenario to be simulated, whilst enabling the necessary work to be undertaken on systems made dead, thus lowering the risks considerably. It is intended that this model is used by maintenance teams during routine shutdowns, and as a means of acceptance-testing new installations.

\section{A. Methodology}

\section{1) Site Obseravtion}

At the site under observation, thermographic analysis has been used to good effect as part of a preventative maintenance strategy. For the purpose of cross comparison, previous reports have proved particularly informative as an indicator of the frequency and severity of faults detected. One of the findings, as shown in Fig. 2, highlights the importance of determining conductor operating temperature in the locality of an electrical joint. In addition, the maintenance department has recently embarked on a program of intrusive inspections and testing, across the installation's rising busbar networks. The measurements recorded during these tests, particularly joint resistance values, have been used in the computation of a thermal model.

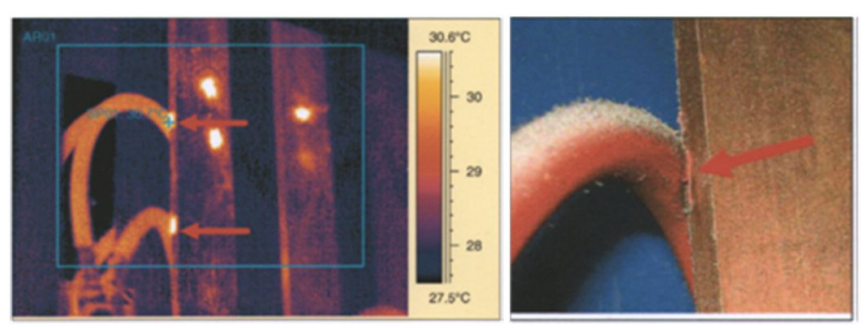

Fig. 2. A published finding in a previous thermographic report commissioned by the building's maintenance department. Source [6].

The components under analysis are the busbar tap-off clamps and cables. These components, pictured in Fig. 3, form the point of connection to associated distribution boards.

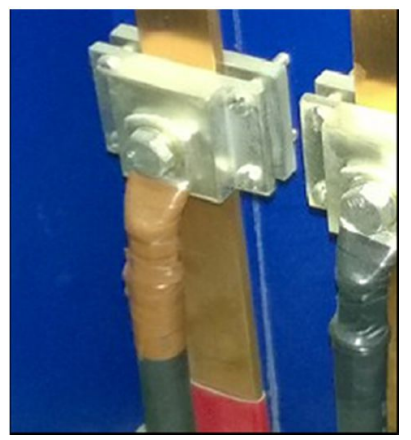

Fig. 3. An example of the type of bus bar tap-off clamp connection under observation.

\section{2) Computational Methodology}

The value of thermal diffusivity, $\kappa$, for copper is $1.11 \times 10-4$ $\mathrm{m}^{2} /$, which can also be derived using (1)

$$
\kappa=\frac{\lambda}{\rho \cdot C_{p}}
$$


Where thermal conductivity, $\lambda$, ensity, $\rho$, and specific heat capacity, $C_{p}$, are known from tabulated values in [7]. The thermal diffusivity of copper dictates that the heat flux emitted from a region of the material will propagate, via conduction, in all directions at a velocity of approximately $10.5 \mathrm{~mm} / \mathrm{s}$; as in (2), where ' $x$ ' is distance in metres and ' $\tau$ ' the time in seconds.

$$
x=\sqrt{\kappa \tau}
$$

It was therefore advantageous to divide the heat transfer system into elements of $10 \mathrm{~mm}$ thickness, $\delta x$, in the direction of heat flows, $Q_{1}$ and $Q_{2}$. Fig. 5 depicts the result of this process. The balance of heat generated and lost in interface elements $\mathrm{A}$ and $\mathrm{B}$ is based on the thermal relationship expressed in Fig. 4.

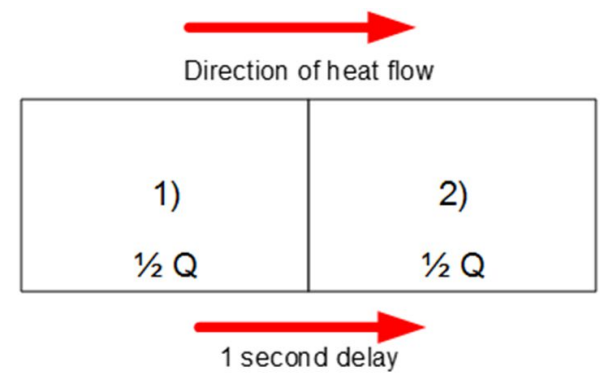

Fig. 4. The relationship between two adjacent elements of a structure, each of $10 \mathrm{~mm}$ thickness

Where heat, $Q$, is produced in element (1) and shared between both elements (1) and (2) over a period of time $\tau \bumpeq 1$ second. $1 / 2 Q$ remains in both elements. In this illustration, losses are not yet considered.

The progressive temperature decay, as a result of heat transported away from the joint, can then be modelled using an application of Fourier's law of conduction. A three-dimensional model of the system under evaluation is shown in Fig. 5. As shown in Fig. 5 for the temperature decay model, each element is numbered sequentially in heat flow direction $Q_{1}$ and $Q_{2}$.

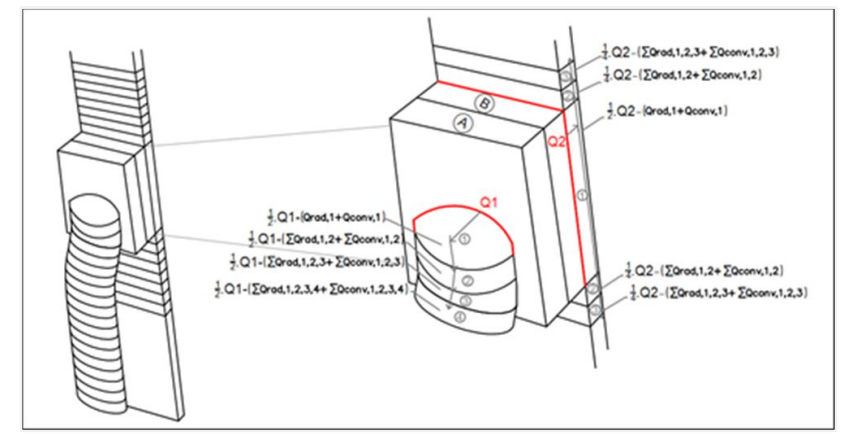

Fig. 5. The thermal model under evaluation, showing material components divided into elements of $10 \mathrm{~mm}$ thickness.

Losses at each notional element for radiation and convection have been computed using Stefan Boltzmann's law of grey-body radiation and Newton's law of cooling respectively, as depicted in Fig. 6.

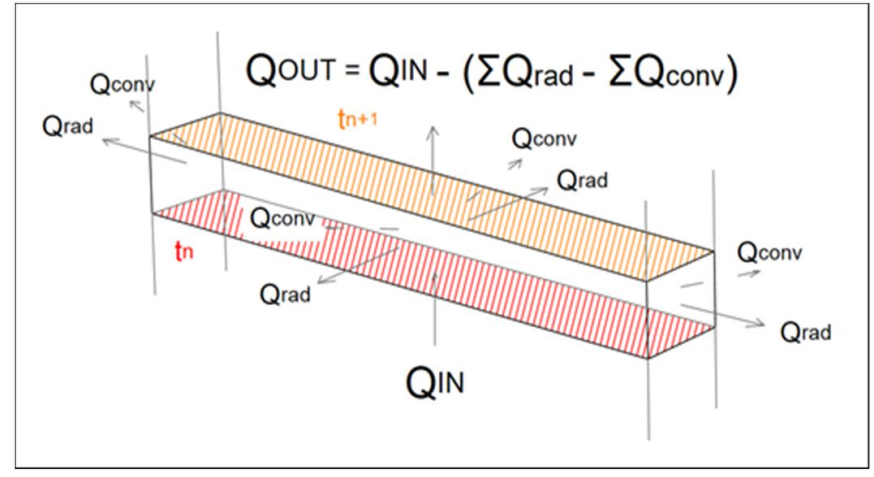

Fig. 6. A Characteristic model of a single element expalining the derivation of the temperature gradient $\partial t / \partial x$ as a function of $Q_{\text {out }}$.

\section{3) Study Analysis}

\section{a. Busbar Temperatur}

The starting temperature for connections is based on the first section of the copper busbar which, by implication, is carrying a current equal to the nominal rating of the protective device for a riser at the test site, of $400 \mathrm{~A}$. Table I below shows an $80 \mathrm{~A}$ current share per floor, across a five-storeys, five sections, LV rising busbar unit.

TABLE I. CURRENT PER FOUR METER BUS BAR SECTION, PER PHASE, USED TO CALCULATE ‘W’ IN EQ. 5.

\begin{tabular}{cc}
\hline \hline Busbar Section & Current (A) \\
\hline Section 1 & 400 \\
Section 2 & 320 \\
Section 3 & 240 \\
Section 4 & 160 \\
Section 4 & 80 \\
\hline \hline
\end{tabular}

The steady state operating temperature of this section is defined by Eq. (4) from [8],

$$
\theta=\theta_{\max }\left(1-\varepsilon^{\frac{-t}{\tau}}\right)
$$

Where $\theta$ is the temperature rise above an ambient condition of $30^{\circ} \mathrm{C}, \theta_{\max }$ is the maximum rated rise of the busbar unit of 30,000 as also defined in [9], $\varepsilon$ is the exponential constant, $t$ is time and $\tau$ is the time constant derived from Eq. (5).

$$
\tau=\frac{Q_{\max } m c}{\omega}
$$

In Eq. (5), $m$ and $c$ are mass and specific heat capacity respectively, and $\omega$ the rate of heat generation in watts as a function of the operating current as shown in Table I and AC resistance relationship. The equivalent $\mathrm{AC}$ resistance was determined using a skin-effect factor of 1.04, derived from Eq. (6). This factor can then be applied to the calculated DC resistance values and substituted in place of $R$ in equation $I^{2} R$, with current, $I$, cross-referenced from the values in Table I. 


$$
S=\frac{R_{f}}{R_{0}}
$$

Where $R_{\mathrm{f}}$ is the ac resistance of conductor, $R_{0}$ is the $\mathrm{dc}$ resistance of conductor, and $S$ is the skin effect ratio.

Inputing these variables yields the operating temperature of each busbar section, for a $20 \mathrm{~m}$ rise consisting of five sections as depicted in Fig. 7.

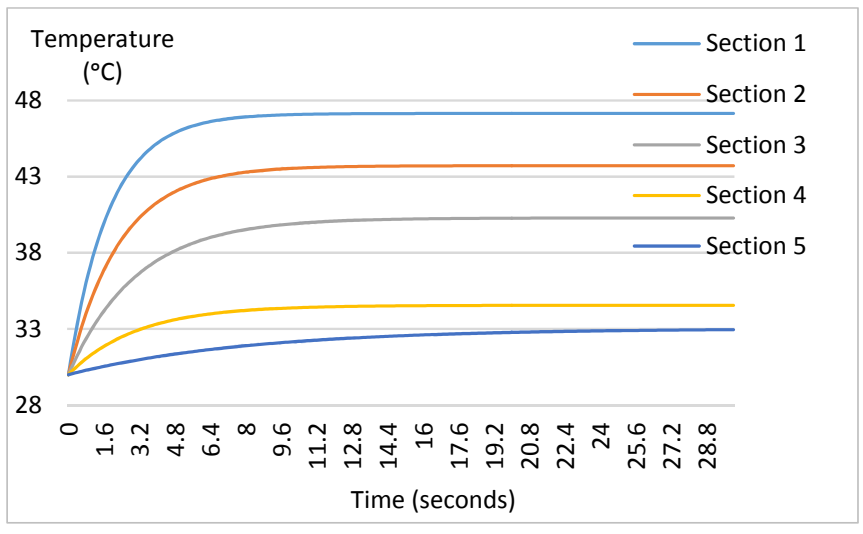

Fig. 7. Bus bar section temperatures with respect to time.

\section{b. Connection Temperature}

After computing the iterative steps of gain and loss at source elements A and B, as shown in Fig. 5, a profile of temperature with respect to time can be successfully plotted, as seen in Fig. 6. A three hour period was chosen due to the foreseeable longevity of peak operating current conditions in a typical sub main circuit. The starting temperature is based on 'section 1' in Fig. 7. Fig. 6 is representative of a joint whose busbar to cable resistance is $180 \mu \Omega$ with an operating current of $100 \mathrm{~A}$ and a connected cable size of $70 \mathrm{~mm}^{2}$. The scenario generated for Fig. 6 would be unacceptable for a PVC insulated cable.

Degradation of the insulation should be expected in the close proximity of the connection; therefore, there is an elevated risk of either a phase to phase or phase to earth fault. The rate of deterioration will depend on the likelihood that the conductor will be carrying $100 \mathrm{~A}$ or more, for a duration exceeding 80 minutes per episode.

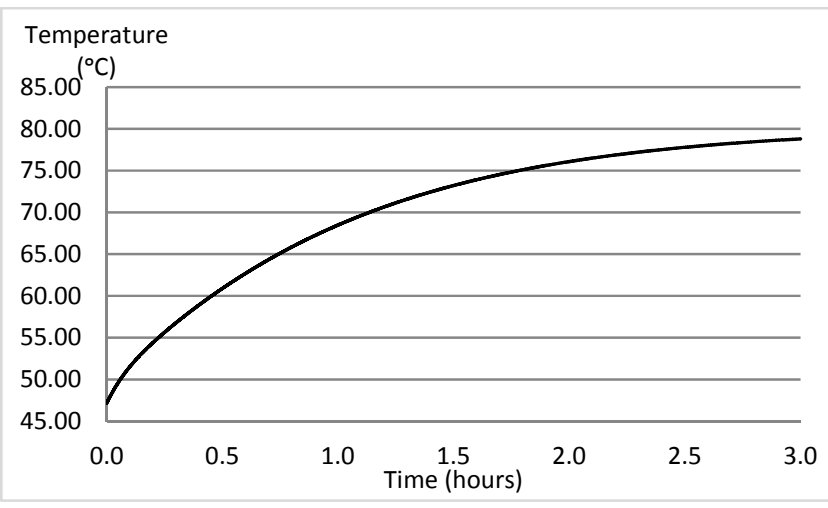

Fig. 8 . The bus bar clamp temperature rise observed with respect to time

To simplify the test result appraisal process, Table II can be used to judge the integrity of connections based on their specific operating criteria. The influence of tap-off conductor size on the rate of heat dissipation from the joint was found to be negligable, hence conductor size has been omitted.

TABLE II. VALUES OF MAXIMUM RESISTANCE FOR UN-INSULATED BUS BAR CONNECTIONS ON INSTALLATIONS WITH AN INSTALLED TEMPERATURE RATING OF $70^{\circ} \mathrm{C}$.

\begin{tabular}{cccccc}
\hline \hline & \multicolumn{5}{c}{ Operating Current } \\
\cline { 2 - 6 } & 60 & 80 & 100 & 120 & 140 \\
\hline $\begin{array}{c}\text { Maximum } \\
\text { permissible } \\
\text { DC joint } \\
\text { resistance } \\
(\mu \Omega)\end{array}$ & 240 & 130 & 85 & 59 & 44 \\
\hline \hline
\end{tabular}

Using the standard calculations for convective and radiative heat loss in the system depicted in Fig. 6, it is possible to render an image showing the temperature decay from the source at each $10 \mathrm{~mm}$ cross-section, see Fig. 9.

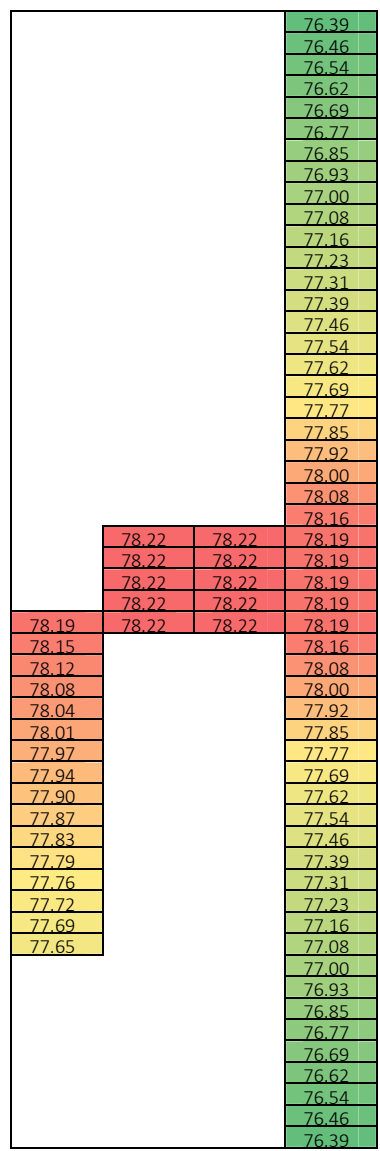

Fig. 9. Thermographic image generated using the finite difference method.

Fig. 9 presents the expected temperature gradient from the bus bar connection conditions previously described and represented in Fig. 8. It shows that the insulation temperature will exceed the maximum rating for continuous operation of $70^{\circ} \mathrm{C}$ at least $160 \mathrm{~mm}$ away from the connection. This increases the risk of a short circuit as it is likely that the conductor insulating material will come into contact with another current-carrying conductor, or the earthed metallic bus bar enclosure. Based on the findings of this study, it is possible to conclude that thermal imagery can 
be produced with minimal risk to the assessor and the customer using this application of the finite difference method. The resistance limits presented in Table II also allow a better on-thespot assessment to be made of a connection's integrity under worst-case-scenario conditions.

\section{ELECTRICAL OVERLOAD PREDICTION}

Protection coordination studies can determine a system's resilience by its ability to disconnect faults at "zone 1"; thus limiting the loss sustained. However, there remains a risk that an overload condition may surpass these controls when the anticipated maximum demand of an upstream protective device is exceeded. Whilst usually generous during the first decade or so of the building's use, the system can easily become compromised after years of progressive expansion, evident in Fig. 1. A key contributor to this effect is the presence of small scale refrigeration and air conditioning plant. When a building's dynamic load contains a large proportion of locally controlled, electrically-driven refrigeration equipment, the coincidental nature of its use warrants a more considered approach to judging the maximum demand.

Conveniently with regard to refrigeration equipment, its power requirement is correlated to the thermal environment. There are several established and experimental techniques used by energy auditors to predict a building's electrical energy consumption with respect to outside air temperature. The purpose of this study is surmise the most appropriate thermal variable to use when determining the risk of overload.

Through identifying a stable relationship between thermal and electrical variables, next-day weather forecasts could potentially be exploited as a tool for assessing the next day peak load and thus, provide a reasonable period of notice in which to implement controls to mitigate overload risk.

\section{A. Methodology}

\section{1) Site Obseravtion}

The case under observation is a single building with an operational central cooling strategy, which employs two absorption chillers which are staged with respect to the building's cooling load. A third and final stage, is afforded by an electric chiller (500kVA). In addition to this, there are 800 small-scale, remotely controlled air conditioning assets, installed to provide supplementary cooling and redundancy for the main systems.

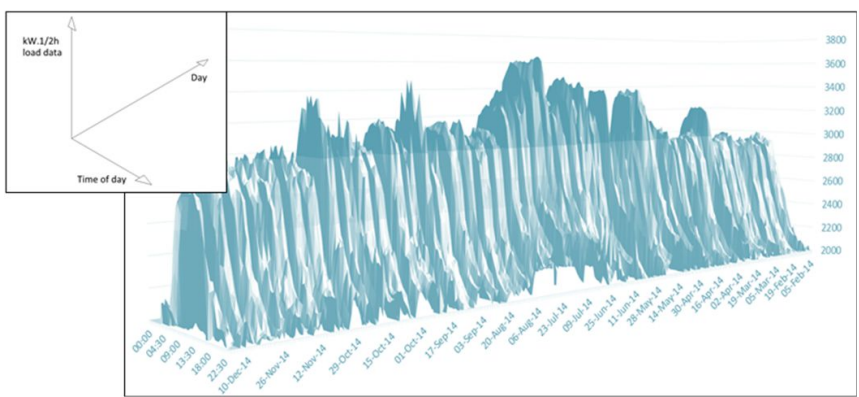

Fig. 10. Site load $\left(\mathrm{kW}^{1 / 2} \mathrm{~h}\right.$ h) with respect to date and time. Energy usage data source [9].

\section{2) Analysis}

The graphical representation of $\mathrm{kW} .1 / 2 \mathrm{~h}$ data with respect to date and time shown in Fig., demonstrates that the site load can be considerably higher during the cooling season. The maximum site load recorded during the test period was $7274 \mathrm{~kW}$, and occurred between 14:00 and 14:30 on $17^{\text {th }}$ July. This finding tends to support the notion that the site electrical load has a strong dependence on the thermal environment.

\section{3) Assessing Thermal/Electrical Load Correlation}

Whilst the predominant cooling method employed during the spring/ summer season is gas powered, using waste heat-driven absorption chillers; a distinct correlation remains between in the total site electrical energy consumption and cooling degreedays, seen in Fig. 11. It can be said that this relationship most likely emanates from the use of small and medium scale, electrically driven, vapor compression air conditioning equipment.

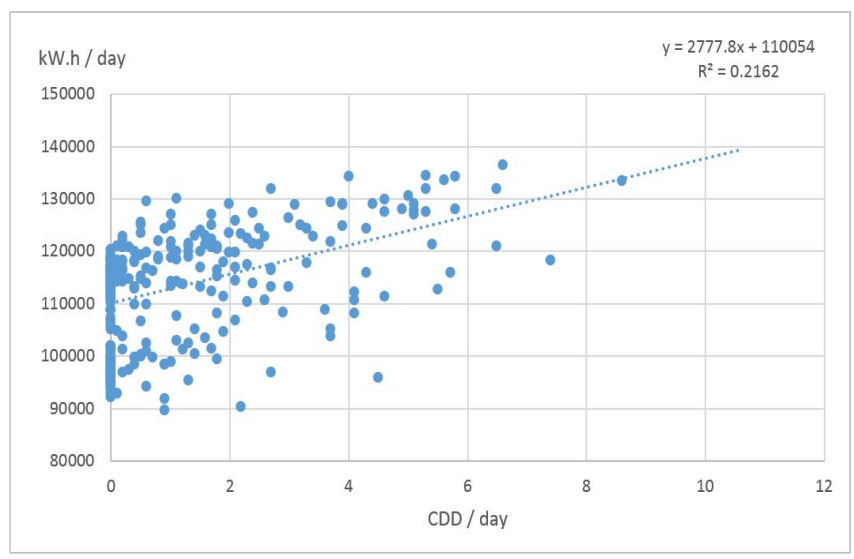

Fig. 11. Daily site energy consumption regression plot with respect to Cooling Degree Days (CDD) per day, weather data source [10], energy usage data source [9].

From Fig. 11, it is shown by the trend line that the site's total daily electrical energy consumption can increase by up to $25 \%$ when there is a need for comfort cooling.

Whilst the regression plot depicted in Fig. 11 serves as a useful indicator, the degree of certainty found between daily electrical energy consumption and CDD is low. This is evident in the associated coefficient of determination, $R^{2}$, which has a value of 0.22 .

Another method of modelling a thermal/ electrical load correlation, is the use of peak values. Fig. 12 displays the relationship between daily peak outside air temperature, $t_{\text {oa_max }}$, and peak daily electrical energy consumption. The data in in Fig. 12 being more closely centered about the polynomial mean, indicates a much greater degree of certainty. From this judgment it is possible to conclude that for this data set, the variables of peak electrical energy consumption and peak outside air temperature, have a much closer dependency on each other than that observed in Fig. 11, and may provide a sufficiently accurate metric for predicting peak electrical load. 


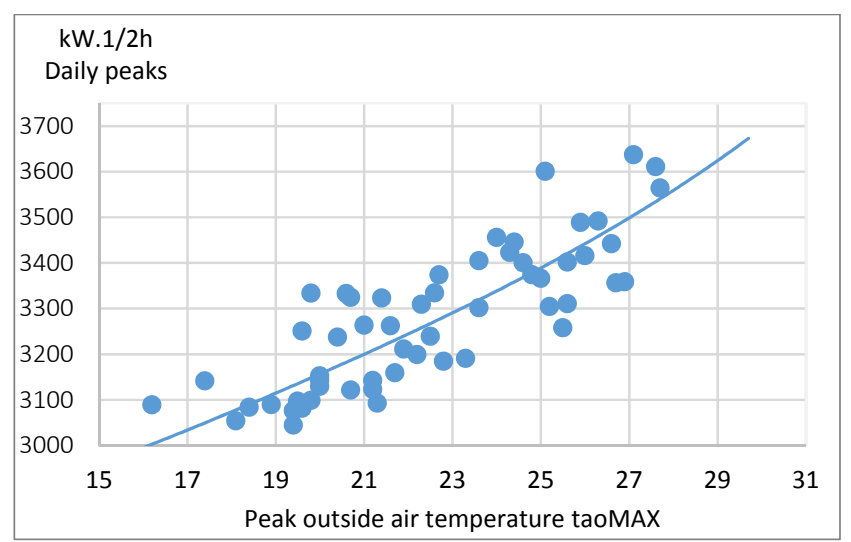

Fig. 12 Maximum recorded site load $\left(\mathrm{kW}^{1 / 2} \mathrm{~h} . \mathrm{h}\right)$ with respect to maximum recorded outside air temperature. $\mathrm{R}^{2}=0.71$. Weather data source: (10), energy usage data source [9].

\section{CONCLUSIONS}

With an ever-growing dependence on information technologies, it is undeniably clear that Resilience Engineering as a concept is, and will continue to be, an important business requirement. In the Healthcare sector where the security of human life is at stake, budgetary constraints should not be a limiting factor, but instead promote determined engineering innovation to protect services. Through the topics discussed in this paper, there remains considerable scope for further development, where the overall aim is to progressively improve the reliability of an organisation's electricity supply, and ultimately, its financial and operational security.

Whilst the engineering principles that underpin studies 1 and 2, may be the logical focal point of this paper, they are in fact facets of a wider, more holistic approach of resilience engineering. An equally vital responsibility for engineering management is the continuing need to set out the powerful investment arguments that are critical to securing the long-term reliability of important engineering infrastructure. After all, resilience must also produce financially viable solutions.

\section{REFERENCES}

[1] Carbon Trust. Carbon Trust. [Online].; 2010. Available from: http://www.carbontrust.com/media/39216/ctv024 hospitals.pdf.

[2] Department of Health. Health Technical Memorandum 06-01: Electrical services supply and distribution Part A: Design considerations Norwich: The Stationary Office; 2007.

[3] Health \& Social Care Information Centre. Hospital Estates and Facilities Statistics. [Online].; 2015 [cited 2015 April 12. Available from: http://hefs.hscic.gov.uk/DataFiles.asp

[4] NHS England. Five year forward view. London:; 2014.

[5] The British Standards Institution. Requirements for Electrical Installations - IET Wiring Regulations BS 7671: 2008 (Seventeenth Edition) 3rd Amendment - 2015. 17th ed. London: BSI; 2015.

[6] Durnhall R. Thermographic Report. Riser Bus-bar Connection Report. Birmingham: Celsius Thermographics Ltd; 2011.

[7] CIBSE. Environmental design. 7th ed. Norwich: Page Bros.; 2006.

[8] Copper Development Association. Copper for Busbars. 2nd ed. Potters Bar: CDA; 1996.

[9] Royal Free London NHS Foundation Trust. 2015. Energy usage data.

[10] Weather Underground. BiZEE Degree Days. [Online].; 2015 [cited 2015 March 15. Available from: http://www.degreedays.net/.

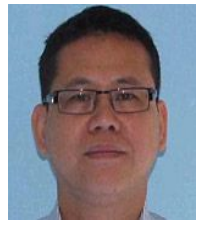

Rusdy Hartungi obtained his B. Eng., in Electrical Engineering, from Hasanudin University, Makassar and M. Eng, in Electrical Engineering from Bandung Institute of Technology, Indonesia in 1981 and 1993 respectively. He is also obtained M.Sc. in Sustainable Development from University of Bristol and MBA in eBusiness and IT from Maastricht School of Management, The Netherland. His $\mathrm{Ph} . \mathrm{D}$ in Electrical Power Engineering from Graz University of Technology, Austria. Dr. Hartungi has a solid research interest in Power Quality and Sustainability. Prior to his current appointment as an academic and researcher at London South Bank University, and previously at the University of Central Lancashire, he was working for many years as a Consulting Engineer working for Multi National Engineering Company in the UK. Dr. Hartungi is an active member of Institution of Electrical Engineer (IEE/IET) and Chartered Institution of Building Services Engineers (CIBSE). He is one of the UK chartered engineers who has gained international recognition as International Professional Engineers, IntPE(UK) as well as European Professional Engineer (Eur Ing). Dr. Hartungi has published more than 30 articles including journals and conference proceedings.

Mr. Commins is a long-standing Facility Manager working for UK National Health Service (NHS) trust. He has seen many issue in relation to resilience faced by health care facility and hospitals. He managed multiple NHS building and has solved various issue relating power quality in NHS. 